\title{
Áreas prioritárias à recuperação e à conservação de florestas naturais no entorno da represa Santa Branca, São Paulo-SP
}

\author{
Patrick Thomaz de Aquino Martins ${ }^{1}$ \\ Joselisa Maria Chaves ${ }^{2}$ \\ ${ }^{1}$ Universidade Estadual Paulista - UNESP \\ Avenida 24-A, 1515, Bela Vista - 13.506-900 - Rio Claro - SP, Brasil \\ patrick_thomaz@yahoo.com.br \\ ${ }^{2}$ Universidade Estadual de Feira de Santana - UEFS. \\ Km 03, BR 116 - Cidade Universitária - 44.031-460 - Feira de Santana - BA, Brasil \\ joselisa@uefs.br
}

\begin{abstract}
The aim of this research is to identify priority areas to the preservation and the recovery of natural forest formations around the Santa Branca dam, São Paulo State. From the definition of Permanent Protection Areas (APP), it was established a buffer of $100 \mathrm{~m}$ and it was analyzed the vegetal covering distribution and also the current use of the ground. It was verified a pattern of land use and vegetation cover reservoir, characterized by the predominance of class pasture/agriculture, followed of forest/“capoeira" and eucalyptus. The remaining percentage was represented by the classes unit urban, exposed soil and water. As the class forest/"capoeira" is the only priority to preservation, this represents almost $1 / 4$ of the total area of APP. The priority area for rehabilitation (pasture/agriculture, eucalyptus and exposed soil) prevails, while those not covered (water and urban unit) have a ridiculous stake. Since this area generates significantly economic resources to municipalities, a management plan for it is necessary.
\end{abstract}

Palavras-chave: geotecnologies, Permanent Protection Areas, Brazilian Forest Code, mapping. geotecnologias, Área de Proteção Permanente, Código Florestal brasileiro, mapeamento 


\section{Considerações iniciais}

Área de Proteção Permanente (APP), de acordo com o inciso II, parágrafo $2^{\circ}$, artigo $1^{\circ}$, do Código Florestal brasileiro, é definida como a "área protegida nos termos dos arts. $2^{\circ}$ e $3^{\circ}$ desta Lei, coberta ou não por vegetação nativa, com a função ambiental de preservar os recursos hídricos, a paisagem, a estabilidade geológica, a biodiversidade, o fluxo gênico de fauna e flora, proteger o solo e assegurar o bem-estar das populações humanas" (BRASIL, 1965).

São consideradas APP as florestas e demais formas de vegetação natural situadas ao longo dos rios ou de qualquer curso d'água desde o seu nível mais alto em faixa marginal; ao redor das lagoas, lagos ou reservatórios d'água naturais ou artificiais; nas nascentes, ainda que intermitentes e nos chamados "olhos d'água", qualquer que seja a sua situação topográfica; no topo de morros, montes, montanhas e serras; nas encostas ou partes destas, com declividade superior a $45^{\circ}$, equivalente a $100 \%$ na linha de maior declive; nas restingas, como fixadoras de dunas ou estabilizadoras de mangues; nas bordas dos tabuleiros ou chapadas, a partir da linha de ruptura do relevo; em altitude superior a 1.800 (mil e oitocentos) metros, qualquer que seja a vegetação (BRASIL, 1965).

Poderão ainda ser consideradas APP, quando declaradas pelo Poder Público, as florestas e demais formas de vegetação natural destinadas a atenuar a erosão das terras; a fixar as dunas; a formar faixas de proteção ao longo de rodovias e ferrovias; a auxiliar a defesa do território nacional a critério das autoridades militares; a proteger sítios de excepcional beleza ou de valor científico ou histórico; a asilar exemplares da fauna ou flora ameaçados de extinção; a manter o ambiente necessário à vida das populações silvícolas; a assegurar condições de bemestar público (BRASIL, 1965).

A ocupação irregular das margens dos reservatórios e mudanças de uso e cobertura do solo nas suas bacias podem afetar a qualidade da água destes reservatórios (PRADO, 2004). Uma ação que poderia evitar esse cenário está relacionada ao cumprimento da legislação vigente. A delimitação de áreas prioritárias a preservação e a recuperação visam identificar quais áreas dentro da APP estão em cumprimento à legislação, a fim de colaborar à manutenção ambiental das formações florestais naturais.

O presente estudo teve como objetivo identificar, a partir da definição de APPs, com base no Código Florestal brasileiro e Resolução CONAMA no 302/02, áreas prioritárias à preservação e recuperação de formações florestais naturais no entorno da represa Santa Branca, estado de São Paulo, utilizando técnicas de geoprocessamento.

\section{Materiais e métodos}

\section{1 Área de estudo}

A represa Santa Branca está localizada no sudoeste da Bacia Hidrográfica do Vale do Paraíba. (Figura 1), Estado de São Paulo, inserindo-se na Bacia do Rio Paraíba do Sul em escala regional. Situa-se no limite político-administrativo dos municípios de Santa Branca, Jacareí, Jambeiro, Paraibuna. Estes municípios totalizam uma população de aproximadamente 214.734 habitantes, sendo que o município de Jacareí possui mais de 96\% desse total.

\subsection{Materiais}

Foram utilizadas imagens de dois diferentes programas espaciais: uma imagem Landsat, sensor TM, ponto 218, órbita 076, de 16 de janeiro de 2008; um mosaico de imagem Landsat 
ortorretificada do programa GeoCover, -10_2000; e um conjunto de cenas CBERS-2B, sensor HRC, datadas de 13 de julho de 2008, ponto 153, órbita 126 (3, 4 e 5).

Os aplicativos utilizados no tratamento dessas imagens, bem como na construção do banco, foram executados em computador PC. Fez-se uso do ArcGIS 9.2, do Global Mapper 10 e do SPRING 5.0.2 (CÂMARA et al., 1996), incluindo o módulo Impima 5.0.

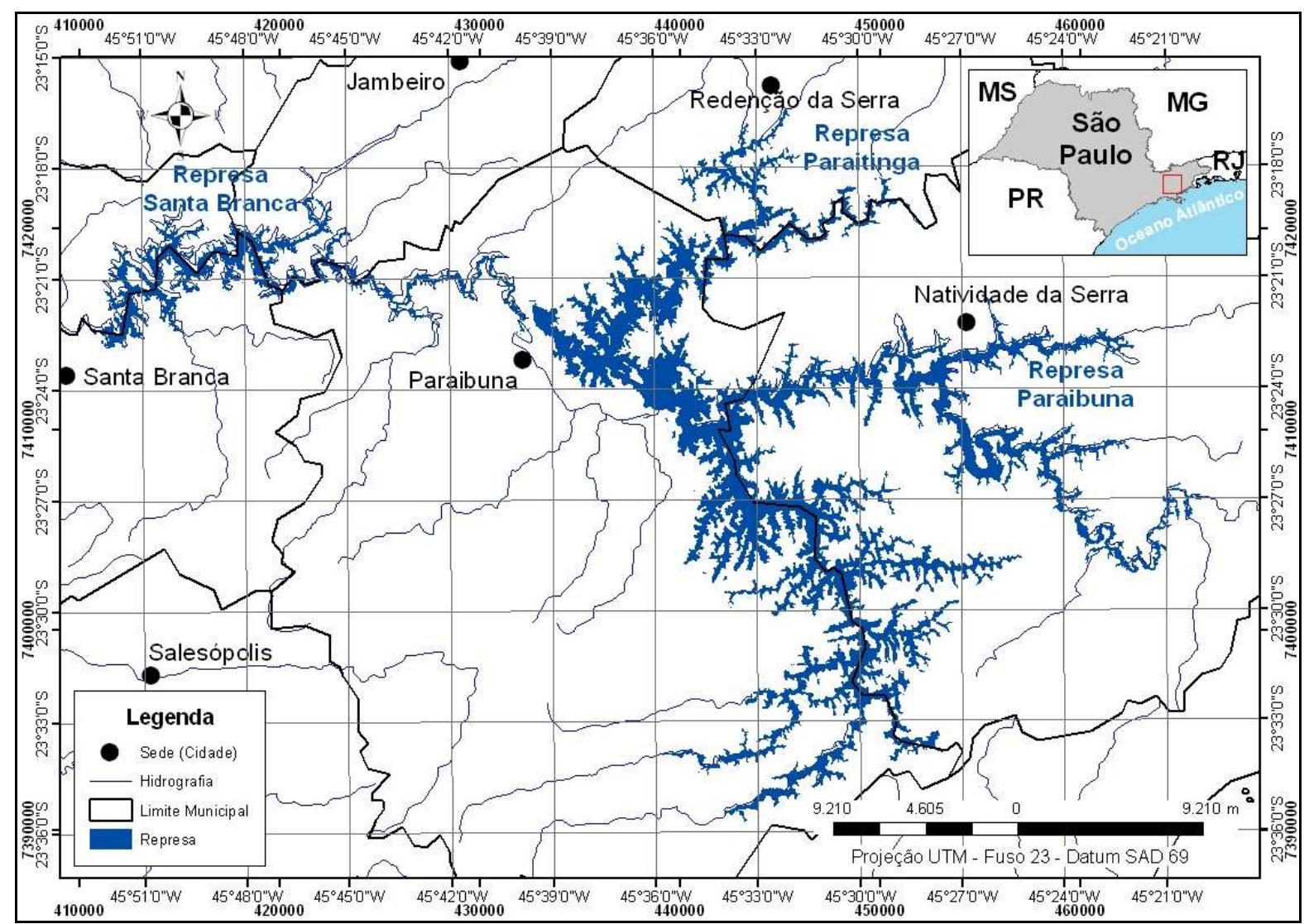

Figura 1 - Localização da represa de Santa Branca.

Fonte: Adaptado de IBAMA (2008), IBGE (2008), PDI.

\subsection{Aquisição e organização dos dados}

As imagens foram adquiridas a partir da rede mundial de computadores (internet), via FTP. Através da base de dados da Divisão de Geração de Imagens/Instituto Nacional de Pesquisas Espaciais (DGI/INPE, 2008) foram obtidas as imagens Landsat e CBERS-2B, ambas em formato GeoTIFF.

A partir do sitio GeoCover (NASA, 2008), foi realizado o download do mosaico de imagem correspondente a área de estudo, em extensão MrSID, a qual foi utilizada como base à correção geométrica das imagens Landsat na fase de pré-processamento.

\subsection{Pré-processamento}

Construiu-se um banco de dados, utilizando como gerenciador o sistema dbase, e estabeleceu-se o projeto de execução utilizando-se a projeção Universal Transversa de Mercator, UTM. Como Sistema Geodésico de Referência, empregou-se o South American Datum1969, SAD-69.

Devido à incompatibilidade do SPRING 5.0.2 com o formato da imagem GeoCover (formato MrSID), foi feito o uso do aplicativo Global Mapper 10 para a exportação do 
GeoCover em extensão GeoTIFF e mudança do sistema de projeção, a qual foi importada ao SPRING 5.0.2, integrando-se ao banco de dados.

A partir da imagem GeoCover identificaram-se pontos de controle, GCPs (Ground Control Points), e procedeu-se a correção geométrica das imagens, adotando-se a projeção UTM e datum SAD-69. A função polinomial aplicada foi a de $3^{\text {a }}$ ordem e interpolador bilinear. Foram amostrados 15 GCPs, adotando-se como padrão os erros médios quadráticos RMS, inferiores a um 0.5 pixel, resultando em 0,271 $(8,13 \mathrm{~m})$ de Erro Médio Quadrático geral (RMS).

\subsection{Realce}

O realce da imagem compreendeu três fases: a escolha da tríade à composição colorida, a aplicação de realce de contraste e a segmentação. No primeiro caso, a combinação foi obtida a partir do cálculo do OIF (Optimum Index Factor), conforme Chavez Jr. et al. (1982). A tríade mais bem classificada foi composta pelas bandas 1, 4 e 5. Estas foram comparadas com as demais, a partir de testes visuais de combinações nos diferentes canais, elegendo a combinação 4R5G1B como a ideal à execução do trabalho.

Como realce de contraste, foi aplicado o contraste linear. Após a aplicação do contraste foi utilizada a técnica de segmentação, algoritmo de crescimento de regiões, com valores de limiar de similaridade e de área, respectivamente, de 25 e 15. As imagens foram então submetidas à classificação supervisionada.

As regiões de classes temáticas foram consideradas com base no conhecimento prévio da área de estudo e na imagem do sensor HRC, do satélite CBERS 2B, na qual foi aplicado apenas um contraste linear.

\subsection{Processamento}

A etapa de processamento envolveu a classificação supervisionada com o algoritmo Bhattacharya, utilizando o limiar de aceitação de 99\%. As imagens classificadas foram convertidas em imagem temática, atribuindo-se cores característica às classes.

\subsection{Pós-processamento}

As imagens temáticas foram transformadas em dados vetoriais, exportadas em formato shapefile e abertas no aplicativo ArcGIS 9.1, onde foi realizada a delimitação de buffers da APP, associação com uma base cartográfica e alimentação do banco de dados.

A delimitação das APPs em torno dos reservatórios seguiu as especificações contidas no Código Florestal brasileiro (BRASIL, 1965) e na Resolução CONAMA n 302/02 (BRASIL, 2002).

As classes identificadas na classificação foram transformadas em classes secundárias, obedecendo aos critérios disponíveis na legislação vigente. As classes tiveram seus layouts de apresentação e representações gráficas organizados e foram analisados.

\section{Resultados e discussão}

\subsection{Identificação da APP}

Apesar de deixar claro, na alínea $b$, artigo $2^{\circ}$, parágrafo $1^{\circ}$ do Código Florestal brasileiro, que ao redor das lagoas, lagos ou reservatórios d'água naturais ou artificiais são consideradas APPs, o código não elucida a faixa marginal a ser considerada. 
Com o intuito de preencher essa lacuna, foi regulamentada, em 20 de março de 2002, a Resolução CONAMA n ${ }^{\circ}$ 302, dispondo sobre os parâmetros, definições e limites de Áreas de Preservação Permanente de reservatórios artificiais e o regime de uso do entorno.

Para efeito desta Resolução, são constituídas as larguras mínimas consideradas APPs no entorno de reservatórios. São estas: de trinta metros para os reservatórios artificiais situados em áreas urbanas consolidadas e cem metros para áreas rurais; quinze metros, no mínimo, para os reservatórios artificiais de geração de energia elétrica com até dez hectares, sem prejuízo da compensação ambiental; quinze metros, no mínimo, para reservatórios artificiais não utilizados em abastecimento público ou geração de energia elétrica, com até vinte hectares de superfície e localizados em área rural (BRASIL, 2002).

No caso da represa Santa Branca, destinada ao abastecimento público, geração de energia elétrica e possui mais de vinte hectares de superfície (SÃO PAULO, 2008), o que elimina as duas últimas condições à delimitação da faixa de APP, ou seja, a faixa não pode ser menor que $30 \mathrm{~m}$.

Devido à complexidade entorno do conceito, definição e diferenciação, sobretudo sob a análise geográfica, das áreas urbanas e rurais, emergindo ainda um termo intermediário, o periurbano (SPAROVEK \& COSTA, 2004), e à ausência de sedes administrativas em uma distância menor que cem metros da margem das represas, toda a área contida dentro desse espaço foi aceito para este estudo como área rural. Essa condição define a largura considerada APP no entorno dos reservatórios aqui estudados como cem metros.

\subsection{Caracterização da cobertura vegetal e do uso do solo}

A distribuição espacial das classes identificadas nas APPs das represas estudadas pode ser observada na Figura 2.

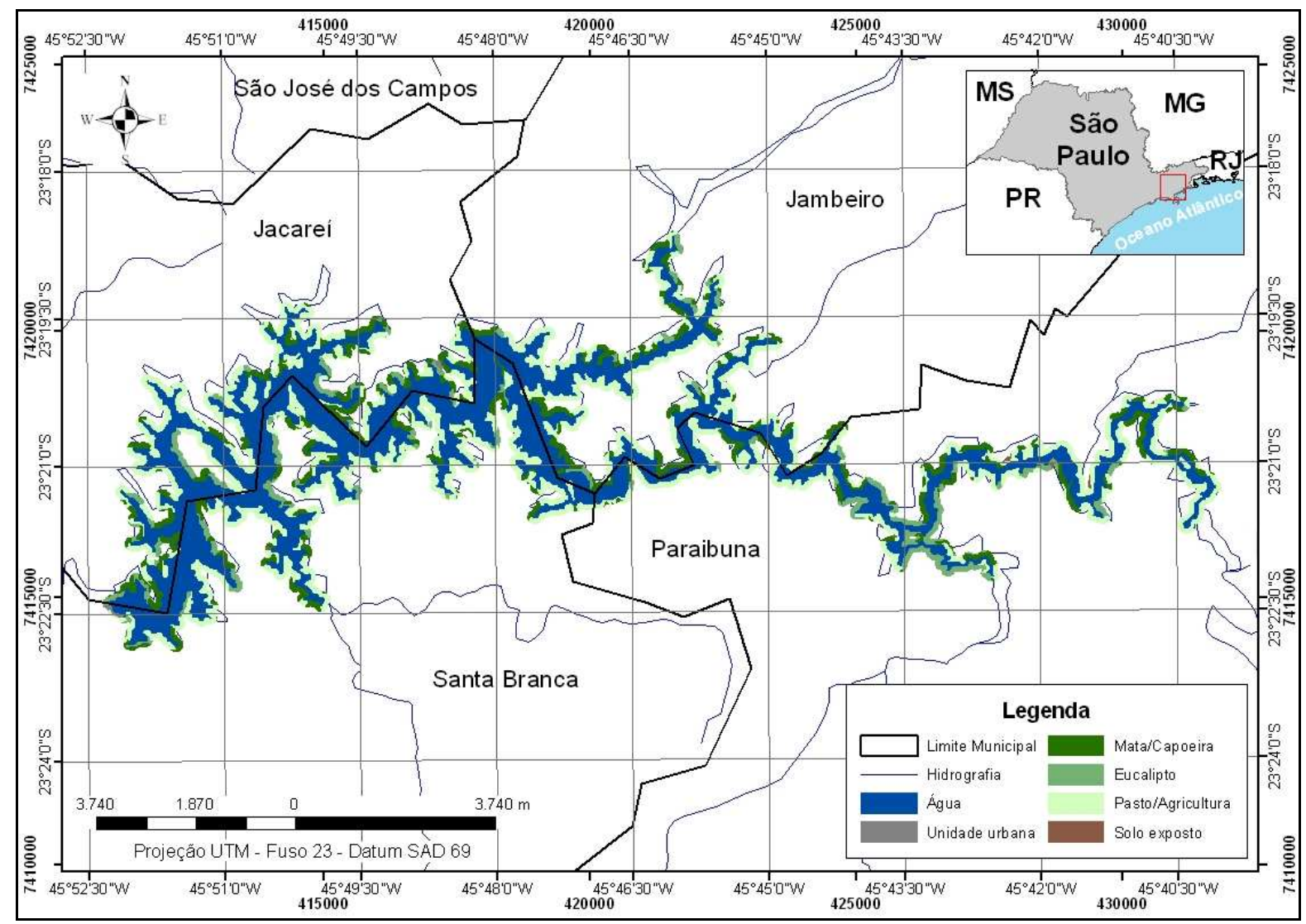

Figura 2 - Mapa de cobertura vegetal e uso do solo na APP da represa Santa Branca. 
Foram identificadas 6 classes temáticas, as quais foram agrupadas da seguinte forma: água, correspondendo aos corpos d'água, ou seja, rios, represas, lagoas, etc.; mata e capoeira, caracterizada pela floresta de vegetação arbórea natural em diferentes estágios (primário, secundário - em regeneração); eucalipto, áreas com eucalipto manejado destinadas à silvicultura; pasto e agricultura, representada pelos campos naturais, pastagem e agricultura de pequeno porte; solo exposto, denotado pela presença de afloramentos rochosos, fraturas de erosão e superfícies recém desmatadas, colhidas ou preparadas ao plantio; e unidade urbana, ou seja, núcleos e aglomerados urbanos, estruturas isolados de concreto, etc. Os diferentes tamanhos das represas ocasionaram diferentes percentuais de cobertura vegetal e uso do solo, embora as mesmas classes estejam presentes no entorno de ambos os reservatórios.

A área total do buffer ocupou 3.903,52ha. Deste, cerca de 49,40\% corresponde a corpos d'água. Considerando que a lamina da represa ocupou uma área de 1.928,14ha, a aérea remanescente, 1.975,39ha, representa a APP.

O percentual restante da classe água é representado pela presença de pequenos corpos d'água, os quais, conforme o Código Florestal, também deveriam possuir APP. Como estes corpos estão incluídos em uma área de APP, torna-se desnecessário a delimitação de uma APP específica para estes.

Esta área está distribuída sobre o território de quatro municípios, Jacareí, Jambeiro, Paraibuna e Santa Branca (Figura 2), os quais detém participação semelhante em áreas da APP, variando de cerca de 400 a 550ha. (Figura 3).

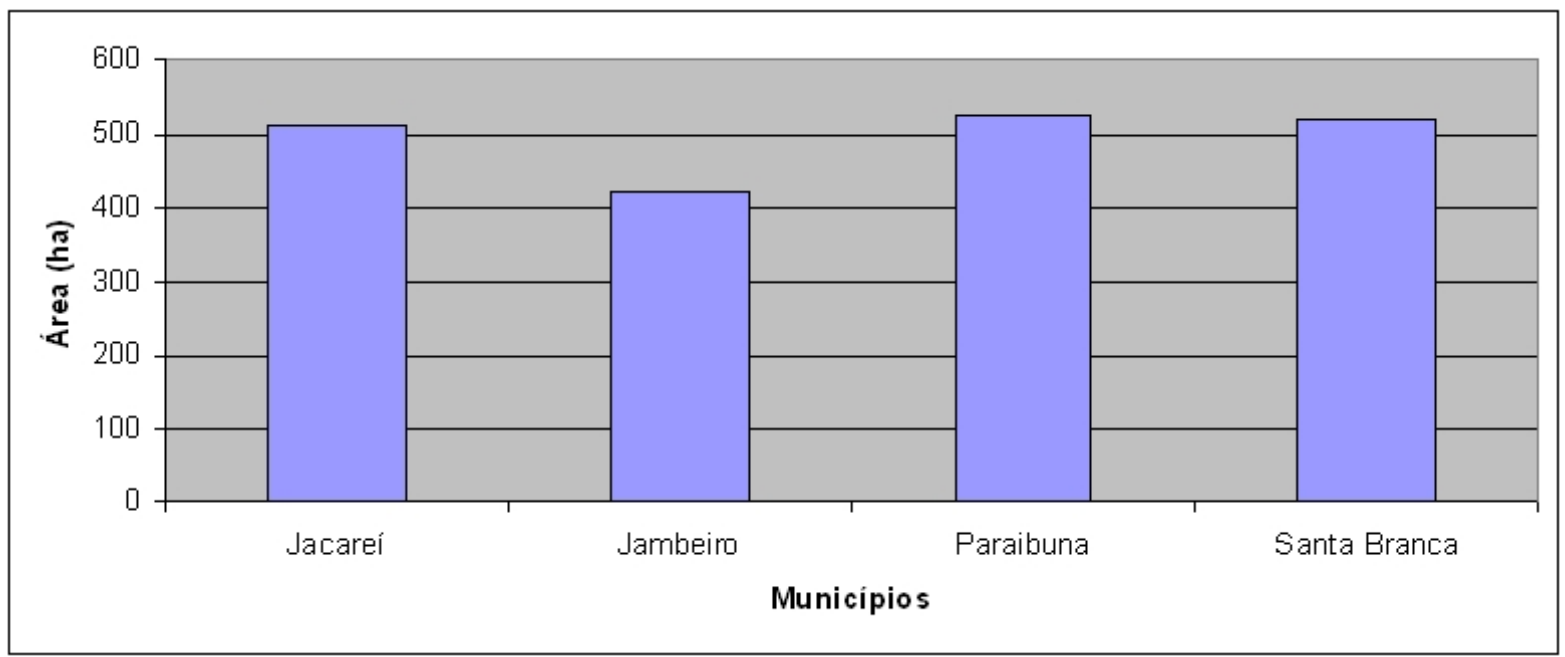

Figura 3 - Área de cada município pertencente à APP da represa Santa Branca.

A APP do entorno do reservatório Santa Branca é dominada pela pastagem e pequenas agriculturas, com mais da metade da área total da APP. A mata e capoeira, classe de cobertura que deveria predominar conforme a legislação ocupa pouco mais de $1 / 4$ da área da APP. A terceira classe mais representativa, eucalipto, somada com a pastagem e agriculturas e a mata e capoeira, completam juntas $99,52 \%$ da área de estudo. O percentual remanescente é ocupado pela classe unidade urbana, solo exposto e água (Tabela 1).

Observando a distribuição das classes por município, temos o mesmo modelo de dominação de classes de cobertura vegetal e uso do solo para a APP de Santa Branca, ou seja, o predomínio de pastagem e agricultura, seguida da mata e capoeira e eucalipto (Figura 4).

A presença do eucalipto está correlacionada com a produção de madeira em tora para papel, celulose e outras finalidades. Este é o único produto da silvicultura presente nos 
municípios estudados e gera uma renda anual de aproximadamente R $\$ 25.000 .000$ (IBGE, 2007).

Tabela 1 - Valores de cobertura vegetal e uso do solo na APP do entorno da represa Santa Branca.

\begin{tabular}{|l|c|c|}
\cline { 2 - 3 } \multicolumn{1}{c|}{} & \multicolumn{2}{c|}{ Santa Branca } \\
\hline Classe & Área (ha.) & \% \\
\hline Água & 0,33 & 0,02 \\
\hline Unidade urbana & 4,93 & 0,25 \\
\hline Mata/Capoeira & 495,18 & 25,07 \\
\hline Eucalipto & 250,08 & 12,66 \\
\hline Pasto/Agricultura & 1220,56 & 61,79 \\
\hline Solo exposto & 4,31 & 0,22 \\
\hline Total & $\mathbf{1 . 9 7 5 , 3 9}$ & $\mathbf{1 0 0}$ \\
\hline
\end{tabular}

A presença de solo exposto na área de estudo pode está correlacionada ao nível d'água no momento do imageamento pelo sensor TM/Landsat, o qual demonstrava estar abaixo do limite máximo, uma vez que muitas áreas de solo exposto estão localizadas nas margens deste reservatório. Quando não localizadas às margens das represas, está pautado na retirada da plantação de eucalipto e demais cultivos agronômicos e ao uso recreativo nas represas.

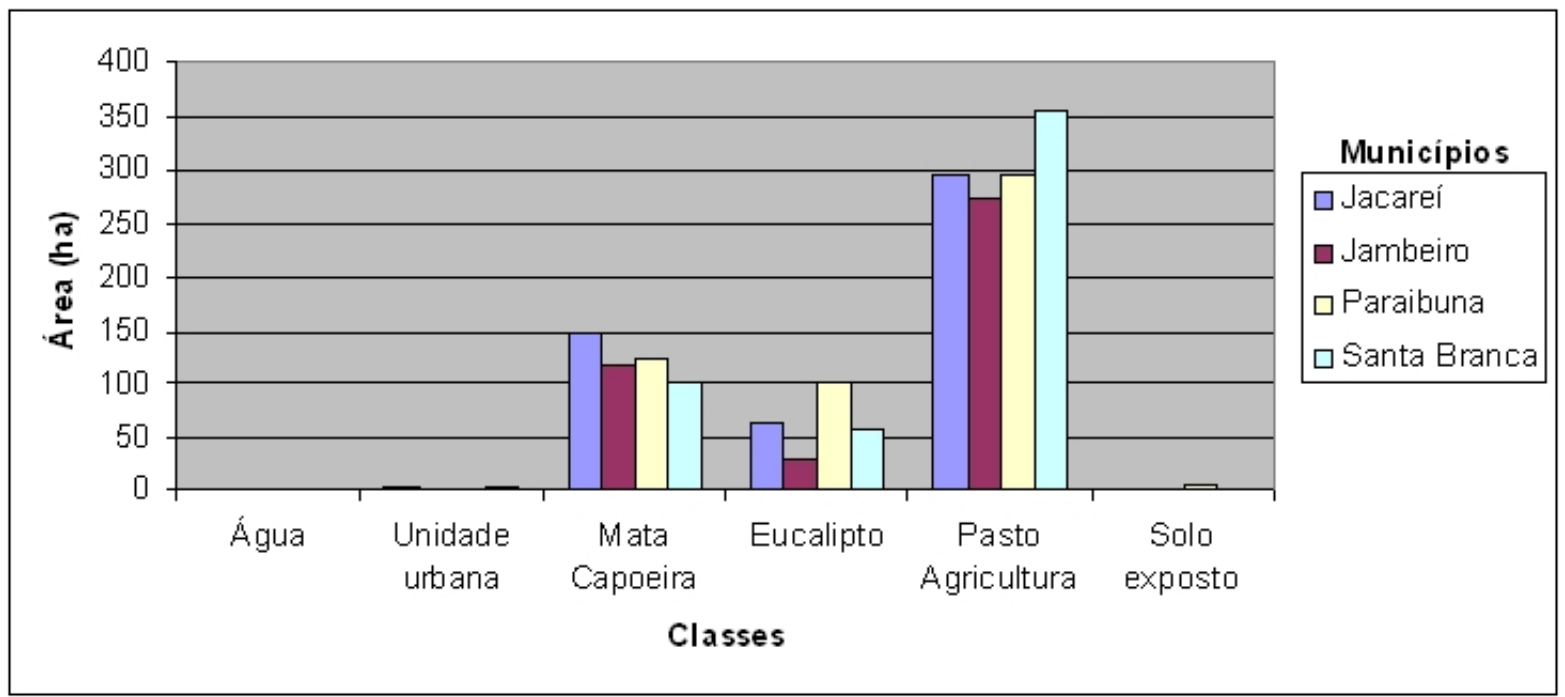

Figura 4 - Área por município das classes identificadas para a APP da represa Santa Branca.

As classes eucalipto, solo exposto e unidade urbana refletem os recursos econômicos presentes nos municípios integrantes dessa região. Dentre as classes identificadas dentro da APP, a unidade urbana merece uma ressalva, pois essas áreas podem ser consideradas "não APP", cabendo, nesse caso, o que estiver disposto nos respectivos planos diretores e leis de uso do solo dos municípios.

\subsection{Definição das áreas prioritárias}

A partir da definição de conflitos no uso do solo e da discrepância dos tipos de cobertura vegetal determinada pela legislação, pôde-se derivar três categorias: áreas prioritárias à preservação; áreas prioritárias à recuperação e áreas não enquadradas.

As áreas prioritárias à preservação são aquelas que estão enquadradas no código Florestal brasileiro e devem ser impedidas ações degradantes, como o corte, a supressão da vegetação, 
ou qualquer outro tipo de agressão. Dentre as classes encontradas, a única que satisfaz essa exigência é a mata e capoeira. Desta forma, as áreas de capoeira poderão se desenvolver estruturalmente a matas primárias e as que são matas podem exercer sua função ambiental.

As áreas prioritárias à recuperação são aquelas que não possuem a vegetação de mata ou capoeira, porém, deveriam tê-la. São, no presente estudo, as classes pasto/agricultura, eucalipto e solo exposto.

As áreas não enquadradas nem como prioritárias à preservação e nem à recuperação são as que possuem elemento urbano, já que para classificar essas áreas em uma das categorias prioritárias deveriam ser feitas análises locais buscando os documentos legais que abordem essa situação; e os pequenos corpos d'água, já que esses também são o agente determinante da APP.

Na figura 5 é possível observar que há um predomínio de áreas a serem recuperadas em detrimento àquelas que devem ser preservadas, ou mesmo as que não se enquadram como APP.

O alto percentual de Áreas Prioritárias a Recuperação na APP justifica-se pela predominância de áreas de pastagem e agricultura. Esse cenário é crítico, pois as áreas que devem ser preservadas representam aproximadamente $25 \%$ e as não enquadradas demonstraram um valor percentual irrisório no universo analisado.

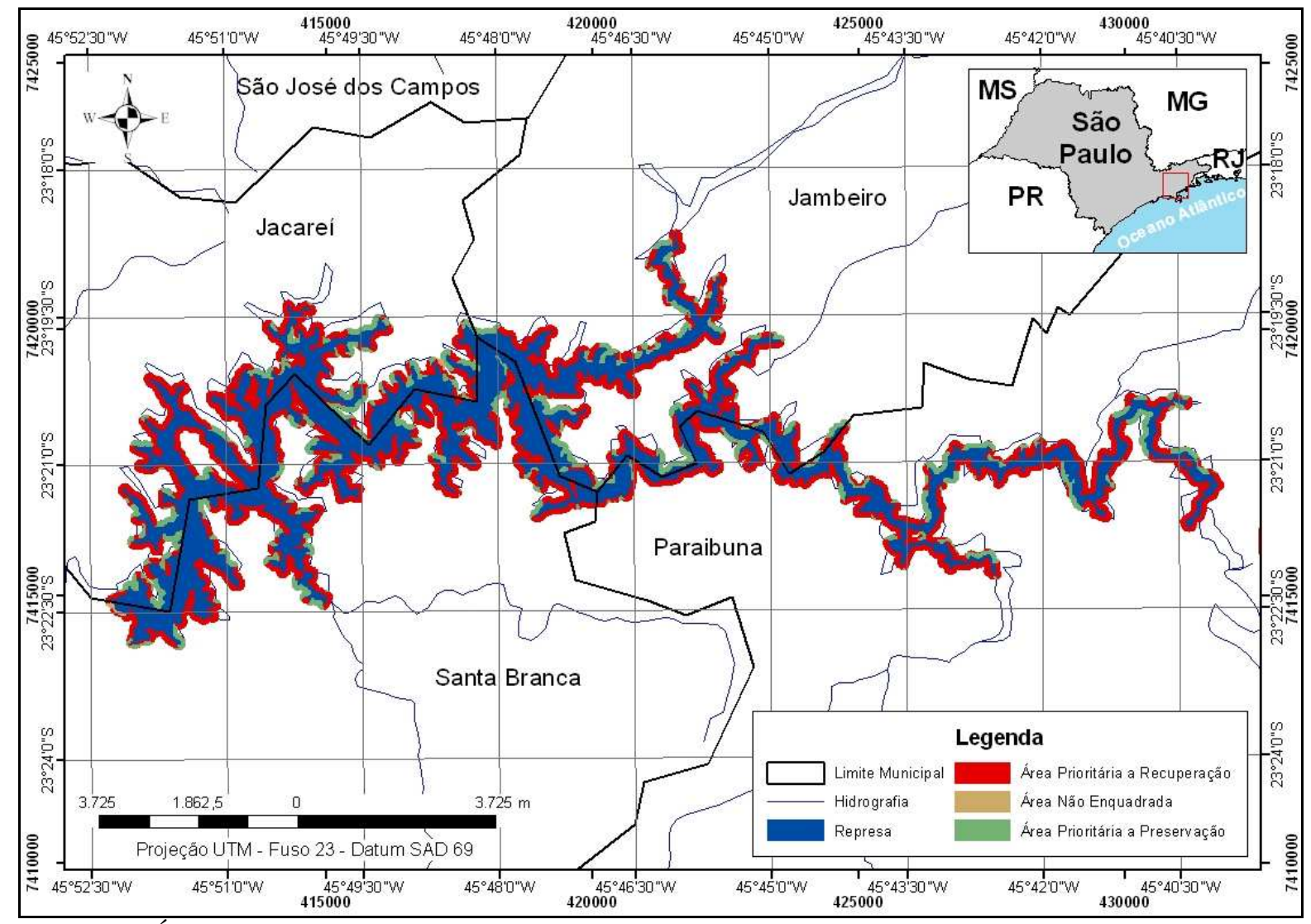

Figura 5 - Área de cada município pertencente à APP da represa Santa Branca.

A presença da classe eucalipto na categoria à recuperação, mesmo sendo esta uma classe florestal de formação arbórea, é explicada devido aos impactos negativos causados por esta em comparação com as florestas nativas, pois a primeira apresenta menor diversidade de espécies, maior degradação no solo e até mesmo redução no aporte hídrico da região quando confrontado à segunda (VITAL, 2007). 
Apesar de ser de responsabilidade da União a fiscalização sobre o cumprimento do Código Florestal, sendo que esta pode ser realizada em convênio com os Estados e Municípios, e não sendo o objetivo do presente trabalho identificar se há infrações ao Código, cabe aos municípios a recuperação das áreas aqui identificadas.

\section{Considerações finais}

O uso de técnicas de geoprocessamento permitiu a delimitação de áreas prioritárias à preservação e à restauração no entorno da represa Santa Branca de forma rápida, precisa e com baixo custo financeiro. A replicação dessa metodologia em outras represas ou mesmo na dinâmica espaço-temporal da represa aqui estudada se faz necessária para que se possa ter conhecimento dos padrões de uso do solo no entorno dessas, bem como na evolução e possíveis cenários futuros conforme tendência observada.

Observou-se a existência de um padrão único, representado pela existência de um déficit de aplicabilidade da legislação incidente sobre as APPs no entorno do reservatório, resultando numa discrepância do uso e/ou cobertura do solo atual em relação àquela norteada pela legislação.

Esse modelo de uso/cobertura faz com que a maior parte da APP seja designada ao reflorestamento de espécies nativas e trás à reflexão qual o real objetivo da existência do Código Florestal brasileiro.

Por gerar recursos econômicos importantes aos municípios, oriundos, sobretudo, da silvicultura e da agropecuária, um plano de manejo dessa área se faz necessário. Este deve ser realizado a partir de uma análise dos respectivos planos diretores e leis de uso do solo municipais, bem como na Resolução CONAMA nº 369 de 28 de março de 2006, que dispõe sobre os casos excepcionais, de utilidade pública, interesse social ou baixo impacto ambiental, que possibilitam a intervenção ou supressão de vegetação em APP.

\section{Referências}

BRASIL. Decreto Federal no 23.793de 23 de janeiro de 1934. Aprova o Código Florestal que com este baixa. Disponível em: <http://www.planalto.gov.br/ccivil_03/Decreto/1930-1949/D23793.htm> Acesso em: 23 nov. 2008

BRASIL. Lei Federal no 4771, de 15 de setembro de 1965: institui o novo Código Florestal. Disponível em: <http://wwwt.senado.gov.br/servlets/NJUR.Filtro?tipo=LEI\&secao=

NJUILEGBRAS\&numLei=004771\&data=19650915\&pathServer=www1/netacgi/nph-brs.exe\&seq=0 00>. Acesso em 26 set. 2003.

BRASIL. Resolução CONAMA no 302, de 20 de março de 2002. Dispõe sobre os parâmetros, definições e limites de Áreas de Preservação Permanente de reservatórios artificiais e o regime de uso do entorno. Disponível em: <http://www.mma.gov.br/port/ conama/legiabre.cfm?codlegi=298>. Acesso em $12 \mathrm{dez}$. 2008 .

BRASIL. Resolução CONAMA n $\mathbf{n}^{\mathbf{3}}$ 369, de 28 de março de 2006. dispõe sobre os casos excepcionais, de utilidade pública, interesse social ou baixo impacto ambiental, que possibilitam a intervenção ou supressão de vegetação em Área de Preservação Permanente- APP. Disponível em: <http://www.mma.gov.br/port/conama/legiabre.cfm?codlegi=489>. Acesso em 27 dez. 2008.

CÂMARA, G.; SOUZA, R. C. M.; FREITAS, U. M.; GARRIDO, J. SPRING: integrating remote sensing and GIS by object-oriented data modelling. Comput Graph, v. 20. p. 395-403.1996.

CETESB. Companhia de Tecnologia de Saneamento Ambiental. Relatório de qualidade das águas interiores do Estado de São Paulo. Secretaria do Meio Ambiente - Série/Relatórios. 273 p., 2003.

CHAVEZ JR., P. S.; BERLIN, G. L.; SOWERS, L. B. Statistical method for selecting Landsat MSS ratios. Journal of Applied Photographic Engineering, v. 8, p. 23-31, 1982. 
DIAS, N. W.; MORAES, E. C.; NOVO, E. M. L. M.; ARAI, E.; CATELANI, C. S. Caracterização das águas da represa de Paraibuna com o uso de dados hiperespectrais. In: Simpósio Brasileiro De Sensoriamento Remoto, 13. (SBSR), 2007, Florianópolis. Anais...São José dos Campos: INPE, 2007. p. 3335-3342. CDROM; Disponível em: <http://urlib.net/dpi.inpe.br/sbsr@80/2006/11.13.23.48>. Acesso em: 16 dez. 2008.

DGI/INPE. Divisão de Geração de Imagens/Instituto Nacional de Pesquisas Espaciais. Catálogo de Imagens. Disponível em <http://www.dgi.inpe.br/CDSR/>. Acesso em 23 jul. 2008.

EMBRAPA. Empresa Brasileira de Pesquisa Agropecuária. Sistema brasileiro de classificação de solos. Brasília: Embrapa Produção de informação, Rio de Janeiro, Embrapa Solos, 1999. 412p.

IBAMA. Instituto Brasileiro do Meio Ambiente e dos Recursos Renováveis. Sistema Compartilhado de Informações Ambientais - SisCom. Disponível em: <http://siscom.ibama.gov.br/>. Acesso em 03 mai 2008.

IBGE. Instituto Brasileiro de Geografia e Estatística. Cidades@. Disponível em: <http://www.ibge.gov.br/cidadesat/topwindow.htm?1>. Aceso: 14 out. 2007.

IBGE. Instituto Brasileiro de Geografia e Estatística. Produtos, Geociências. Disponível em: <http://www.ibge.gov.br/home/geociencias/default_prod.shtm>. Acesso em 05 mai 2008.

NASA. National Aeronautics and Space Administration. GeoCover. Disponível em: <https:// zulu.ssc.nasa.gov/mrsid/mrsid.pl>. Acesso em 24 jul. 2008.

PRADO, R.B. Geotecnologias aplicadas à análise espaço-temporal do uso e cobertura da terra e qualidade da água do reservatório de Barra Bonita, SP, como suporte à gestão de recursos hídricos. São Carlos. Tese (Doutorado). Centro de Recursos Hídricos e Ecologia Aplicada, Escola de Engenharia de São Carlos, Universidade de São Paulo, 2004.

SÃO PAULO. Sistema de Informações para o Gerenciamento de Recursos Hídricos do Estado de São Paulo: Paraíba do Sul. Disponível em: <http://www.sigrh.sp.gov.br/sigrh/ ARQS/RELATORIO/CRH/1063/ugrhi_02_04.pdf> Acesso em 20 abr. 2008>.

SPAROVEK, Gerd; COSTA, Francisca Pinheiro da Silveria. Evolução urbana e da cobertura vegetal de Piracicaba-SP (1940-200). Caminhos da Geografia, Uberlândia, v. 5, n. 13, p. 65-88, 2004.

VITAL, M. H. F. Impacto ambiental da floresta de eucalipto. Revista do BNDES, Rio de Janeiro, v. 14, n. 28 , p.235-276, dez. 2007. 